\title{
Patriarchy rules: Transforming Resistance to gender inequalities in science teacher education in Zimbabwe
}

\author{
Charles Chikunda, Research Associate, Department of Education, Rhodes University \\ charles@ award.org.za or cchikunda2@gmail.com \\ Plaxcedes Chikunda, Lecturer, Sociology of Education, Great Zimbabwe University \\ pchikunda@gmail.com
}

\begin{abstract}
This paper explores underlying mechanisms that constrain gender transformation in science education in Zimbabwe. Notwithstanding strides made with regards to gender equality in education, gender disparity is still visible mostly in natural science related disciplines. Focusing on a teacher education department, this paper argues that gender inequality is deeply imbued in the norms of the institution, patriarchy as a culture playing a decisive role in constraining the uptake of gender responsive curriculum practices. As recommendation we propose that curriculum re-orientation is not likely to be successful if it is done superficially without shaking the patriarchal roots that shape cultural values of practitioners. There is need to go beyond policy formulation to support reflexivity among teacher educators that will help them to scrutinize their values and practices as it relates to establishing gender responsive pedagogy in science education.
\end{abstract}

Keywords: Patriarchy, resistance, gender responsive pedagogy, Science, Mathematics and Technical subjects, teacher education, Zimbabwe.

\section{Introduction}

The significance of gender equality for development is widely recognized globally. Economic and social development in any country, under modernity, relies heavily on a sound scientific and technological base. This can be achieved by putting emphasis on Sciences, Mathematics and Technical subjects (SMTs) at all levels (Hopkins and McKeown, 2005; Clegg, 2007). There is need therefore for any country to harness the intellectual and scientific capacity of both men and women for sustainable social, ecological and economic development. Yet, SMTs constitute the areas within the educational system where gender disparity is greatest, in several of the poorest countries of the world (Clegg, 2007; Sinnes, 2004). Despite the documented benefits to economic and social development of granting females education, relatively fewer girls than boys are given the opportunity to participate and perform in SMTs education disciplines in several of the poorest countries of the world (ibid.). There is also evidence that in most countries, perhaps all the countries of the world, technological careers are far more likely to be taken up by men. These careers tend to be financially more rewarding and are often seen to be more prestigious than those predominantly occupied by females (MacKay and Parkinson, 2010). In Zimbabwe for example the percentage of men and women in Faculties of Science is 76/24 and the situation is not very different in other African countries (Morna and Jambaya-Nyakujara, 2011). Our intention in this paper therefore was to explore some of the underlying mechanisms that constrain the transformation of gender disparity in SMTs in Zimbabwe. 


\section{Efforts towards gender equality amidst resistant structures}

There are however some historic efforts to close the gender gap in SMTs education which cannot be ignored. For instance using guidelines from international bodies such as Education for ALL (EFA) and the Millennium Development Goals (MDGs), the Zimbabwean government like most governments worldwide came up with policies to guide curriculum development with gender equality in mind. The Zimbabwe National Gender Policy is an outstanding tool that was designed to direct education institutions in the country to be gender responsive. In its Education and Training sector, the policy specifically outlines the following as some of the strategies: amend all relevant education and legal instruments to promote gender equality and equity; incorporate gender issues in all curricula at all levels of education; eliminate all forms of discrimination against boys and girls in education and skills training which includes science and technology; promote and encourage girls to take on science, mathematics and technology at all levels of education and introduce gender awareness programmes to pre- and post-training teacher courses (National Gender Policy, 2004; p. 9). It should be commended for inspiring a lot of progress to be made with regards to gender and education in general. For instance the Status and Trends in the Zimbabwe MDGs status report (2010) shows that Zimbabwe has consistently maintained relatively high levels of primary school enrolments for both sexes. For the MDG goal 3 , the 2010 MDG country report shows that while there is gender parity at a primary school level, and near gender parity at lower secondary level, particularly in the lower forms (Forms 1 to 4), the gender parity decreases in upper levels, where there are low representation and completion rates amongst girls leading to a low enrolment of women in universities generally, but more so in the fields of sciences. In our view, teacher education should play a leading role in addressing transformation. It is for that reason that the study sought to unearth some of the mediating factors that may constrain gender responsive pedagogy in SMTs.

In exploring mediating factors that may constrain gender responsive pedagogy in SMTs, we saw it befitting to start by highlighting the generic historical and structural inequalities experienced by women in the education system before focusing specifically on gender issues in SMTs. Zimbabwe is a patriarchal society, and many writers (for example Chikunda, 2010, 2013; 2014; Dorsey, 1996; Gordon 1995; Mutekwe and Mutekwe, 2012; Nhundu, 2007) share the sentiments that patriarchal values embodied in the school curriculum make girls as a whole disadvantaged, when compared to boys as a whole.

Looking at the influence of gender ideology in school curriculum (Mutekwe and Mutekwe, 2012) point out that children learn at a very early age in their schooling to identify masculine and feminine roles particularly in relation to broad categories of behaviour, characteristics of the division of labour both in the home and in the occupational structure of society. They add that at an early age, children internalize important elements of the ideology about the different roles that men and women, or boys and girls play in their society. In addition to this, children themselves soon come to learn to identify with the appropriate gender roles expressing them in different forms of overt behaviour which manifest in their everyday lives (ibid.). At school level, the gender ideology manifests itself in a variety of ways including subject choices whereby girls pursue in the main those subjects which are considered as more appropriate for females such food and nutrition, fashion and fabrics and the arts.

The prevalence of patriarchal values in the curriculum is a feature that characterizes the education system in Zimbabwean. Patriarchy is a set of social relations between men and women, which has a material base, and which through a hierarchical system creates interdependence and solidarity among men that enable them to dominate women (Nhundu, 
2007). Aspects of the hidden curriculum such as the gender typing of school subjects and occupations were cited as some of the prevalent practices that bolster patriarchal values by Mutekwe and Mutekwe, (2012). Sexual harassment as one of the issues that buttresses the patriarchal ideology is reported in many studies (Dorsey, 1996; Gordon 1995; Mutekwe and Mutekwe, 2012). Mocking, humiliation, verbal abuse and the unnecessary ridicule of girls by boys are some of the forms of sexual abuse endured by girls in the school often leading to some girls resorting to withdrawal and consequently to underperforming academically. To make matters worse, teachers tend to collude with male pupils in the sexual harassment of girls in the school, either subtly, by omission or directly as noticed by Mutekwe and Mutekwe (ibid.).

With regards to the discrepancy in performance, teachers often blame girls' acceptance of the feminine role as primarily domestic and the belief that a man should be the provider and head of the family as the major causes of the performance discrepancy between girls and boys (Chikunda 2014; Mutekwe and Mutekwe, 2012). In general, teachers' attitudes, beliefs about gender abilities and their labeling and characterization of females as people with different abilities and aptitudes compared to males, are mirrored in the attitudes, values, ideologies and beliefs of girls themselves. Chikunda (2010) found out that teachers are to a large extent unaware of or unwilling to admit to the role they play in influencing girls' self-concepts in school and later in life. To the contrary, a common belief or misconception among teachers is that the causes of girls' underachievement lie outside of the school, in the girls' homes or within the girls themselves (Mutekwe, et al 2013). It is a concern that such a view sort of exonerates the teachers and the school from any of the responsibility of attending to gender issues in education.

Learning support materials too are not free from patriarchal values, notwithstanding the efforts done by the ministry of education since independence in 1980, to rid books of sexist language. The content analysis of history textbooks done by Mutekwe and Mutekwe (2012), revealed that the ideology inherent in the books accords women a lower status compared to their male counterparts in as far as political activism is concerned. Through such ideologies women are portrayed as having played an insignificant role in the liberation fight for Zimbabwe. Arguing from a feminist standpoint, the authors claim that the net effect of such a portrayal of men is meant to entrench or buttress the ideology of patriarchy while relegating women to a secondary position on the political hierarchy so as to justify the inequality that often accompanies role selection and allocation in the political sphere of the country.

Socialization both at home and in school also plays a role in hindering girls' progress in science especially in most African societies that are patriarchal. Teachers who are central to the transformation of society in general, and the school system in particular, are a product of gender construction in any society. In most African communities, teachers, like their students, are socialized in basically patriarchal structures that foster gender inequality economically, socially and culturally. Examples of gender inequality in most African societies include attitudes and practices that see women as basically inferior to men, without the right to ownership of the means of production and property Kalu (2005). A critical look at the Shona culture shows some of these misconceptions. Rutoro et al (2013) came up with gendered illusions about the intellectual makeup of men and women, which in our view requires attention if gender transformation in SMTs is to become a reality. Men versus women are portrayed in culture as (ibid., p. 2), 
Good decision makers-Poor decision makers regardless of age;

Good judgment-Poor in making judgment;

Problem solvers-Slow thinkers \& Poor at problem solving;

Rational-Irrational;

Visionaries...they think ahead-Think of just the present.

\section{Male patterns of dominance in science}

At a global level gendered curriculum practices in SMTs have been researched over the years. In terms of curriculum practices, most studies point to the lack of gender responsiveness in the pedagogy applied in schools as one major hindrance to improving access, retention and performance of females in sciences (Madziva, 2000; Kalu, 2005; Clegg, 2007; Chikunda, 2010; Christidou, 2011; Chetcuti and Kioko, 2012). All these studies point to traditional male patterns of dominance inherent in the conceptualization, history and theorization of SMTs as key constraints to gender transformation. In the case of Zimbabwe, it seems that even whilst it is common knowledge that gender imbalances exist in SMTs, teachers are often unaware or unaccepting of the situation, and would not naturally feel the need to address such issues (Chikunda, 2013). The question to be asked now is whether teacher education is doing enough in Zimbabwe to prepare teachers to be gender responsive in the education system into which they are going.

Male dominance in SMTs is also visible in staff representation. Mawere (2013) discovered that in teacher education institutions, females constitute only $21.6 \%$ of lecturers in sciences. Similar trends are observable in technical and vocational institutions as well as in related university faculties. Teachers and learning support materials are also blamed for promoting male scientists and downplaying the role played by female scientists. At the international level, Wertheim (1995) pointed out that the sole female scientist that most people can name is Marie Curie, and yet there are so many other female scientists who have won Nobel prizes in science; these include Dorothy Crowfoot Hodgkin, Barbra McClinton and Getrude Elion. Girls therefore do not get the necessary exposure to both current and historical female role models that could provide encouragement and inspiration in the field of science. In Zimbabwe, science curriculum specialists who have attempted to incorporate indigenous knowledge into school science are not spared from the patriarchal values either. For example, Ndawi (1987) encouraged the use of traditional artefacts such as catapult, stone trap, bow and arrow to develop scientific concepts such as force, movements, velocity and kinetic energy in physics. The idea of bringing in indigenous ways of knowing into school science is welcome and is useful to African students to link their lived experiences with school science. Nonetheless, most artefacts used as teaching learning models are those traditionally used by males in society. It is likely that some girls would be seeing the artefact for the first time in science classes.

Other science curriculum critics see school science as usually fragmented into different, strictly isolated disciplines, and/or presented in contexts of limited interest for students, thus failing to provide students with a coherent picture (McSharry and Jones, 2002; Siegel and Ranney, 2003). This perspective of science and related SMTs disciplines is similar to what Aikenhead (2002) called scientism. ${ }^{1}$ The perspective was proposed after the realisation that science teachers the world over tend to harbour a strong allegiance to the values of scientism, yet conventional science teaching, claiming to transmit value-free knowledge to students, subliminally inculcates

\footnotetext{
${ }^{1}$ The belief that science is authoritarian, non-humanistic, objective, purely rational and empirical, universal, impersonal, socially sterile and unencumbered by human bias, dogma or cultural values. 
scientific as well as societal values (ibid.). Chikunda, (2010; 2013) discovered that Zimbabwean teachers who believe in the values of scientism tend to ignore other forces such as students' and teachers' home background and patriarchy that influence science knowledge and its uptake in schools.

\section{Resistance to gender curriculum transformation in Zimbabwe}

In this section we use language to explore resistance to gender transformation in science teacher education. We draw on data generated in our previous studies (Chikunda, 2013; Chikunda and Chikunda, 2015) to showcase how patriarchal values can inhibit gender curriculum transformation. We take a cue from Daniels (2012) who argues that "talk shapes and is shaped by thought; talk is situated, institutions shape talk and talk shapes institutions and institutional talk shape practices" (p. 2). We employ feminist lenses to describe, interpret, analyse and critique curriculum practices as written in texts and spoken words to reveal gender biases, discrimination, blindness and so forth, and how these are initiated, maintained, reproduced and act as a barrier to gender responsive curriculum practices in SMTs teacher education. As shown in Chikunda (2013), data was generated under two themes; knowledge/ perceptions on push out factors for girls from SMTs and the Role that teacher education can play to improve the participation of females in MTs. For each theme, teacher educators ${ }^{2}$ responded to a lead question as shown below (ibid., p. 237).

Discourse fragment 1: Lead question: Why do you think girls become less and less interested in sciences as they continue with their education?

\section{Participants (several interviewees)}

int1: They [girls] believe that science is for boys/is difficult, they put less and less effort in science as they proceed in high school education, some even start love relationships.

int5: Girls are socialised to do easier stuff, some look up to men to look after them in life...

int3: Girls are capable/able but they put less effort at a certain level in their studies. Information Technology is lifelong learning it depends on the character of the person ... females not willing to continue learning...

int2: At F3 (G10) they have acquired a gender identity and they want to be recognised as such by male counterparts ... implication ... it is unfeminine to be good in physics for example. Opportunities towards education for all are there, the fault is theirs (girls) not the system. Some even start love relationships...

To interpret this data, we drew on Fairclough's (2008) three functions of linguistic analysis: representation, relations and identities. The representation function (ideational function) looks at particular representations and re-contextualisations of social practice (Sheyholislami, 2008). In this case, girls are represented as "weak, putting less effort, used to get things done for them", therefore "the fault is theirs". The sentence "girls are socialised to do easier stuff" in the above extract is ideationally loaded.

\footnotetext{
${ }^{2}$ Discourse fragments came from experienced male SMTs teacher educators, raised in a typical Zimbabwean patriarchal culture.

Cultural and Pedagogical Inquiry, Fall 2016, 8(2), pp. 11-22

ISSN 1916-3460 @ 2016 University of Alberta

http://ejournals.library.ualberta.ca/index.php/cpi/index
} 
Identities are particular constructions of writer and reader identities, and reflect status and role aspects of identity or individual and personality aspects of identity highlighted in the text (ibid.). All the sentences in this text articulate that girls are not motivated to do science. In fact, the discourse fragments portray girls as lazy and unmotivated, a group of people who look forward to be looked after in life. The socially constructed feminine identity evident here is also stereotyped to be anti-science.

By relationship, Fairclough (2001) means a particular construction of the relationship between producer of text and the one referred to in the text (as for instance, close or distant, formal or informal). Although not explicit in the text, one is tempted to deduce that such statements are uttered by teacher educators who do not maintain a close curriculum relationship with female learners. They have lower expectations of them and the relationship is likely to be cold. Lower teacher expectations are detrimental to girls, as observed by Kalu (2005) in Nigeria, who found that in SMTs, there is a relationship between lower teacher expectations for female performance, and a negative self-image of female students. By extrapolation, the vicious cycle is likely to be perpetuated, if teachers show lower expectations of female students, female students perform less or quit SMTs outright.

According to Fairclough (2008), linguistic analysis is also concerned with presenting as well as absenting. Conspicuously absent in this text are many other push-out factors for girls from SMTs some of which are reported in literature section above. The only aspect that is presented as causal for girls' avoidance of sciences is their identity implying that SMTs teacher educators do not know of other factors that impede girls in SMTs.

The second dimension relates to discourse practice. It looks at context at the micro level. It raises questions on power relations, merging voices and relies on intertextual analysis, looking at ways in which the text straddles society (Fairclough, 2001). Analysis of the discourse fragment in this case clearly shows some intertextual traces or snatches of patriarchal ideology. This is shown by the undervaluing of women's and girls' work. This is despite overwhelming research evidence showing that women work more than men in patriarchal societies (Kabeer, 1994), and that from an early age girls are socialised to do reproductive, productive and community work ${ }^{3}$. This opinion emanates from patriarchal societies that only value productive work that is paid for in the capitalist world. The statement "at F3 (G10) they have acquired a gender identity and they want to be recognised as such by male counterparts..." is again ideologically loaded. Implicit is the fact that girls acquire their value, worth, identity etc. through the eyes of males. This greatly underrates their personhood, individual identity and agential powers. Fraser calls this misrecognition, "the manner in which individuals or groups are marginalized, degraded or oppressed by social and cultural practices" (cited in Dieltiens et al., 2009, p. 367).

The last piece of the discourse fragment "some even start love relationships" could be linked to gender role stereotypes found in most patriarchal societies that view reproductive roles (marriage

\footnotetext{
${ }^{3}$ Productive roles: relate to the production of goods for consumption or the generation of income through work within or outside the home. In many societies men have more visible and recognised productive roles than women, largely because men are more commonly paid for their productive work and women are not. Reproductive roles: relate to domestic or household tasks associated with children and family.

Community management roles: involve a wide range of activities undertaken voluntarily by men and women in the community with the common purpose of benefiting the community as a whole. Activities include: the collective organisation of social events and services, ceremonies and celebrations; initiatives to improve the community, participation in groups, clubs and organisations etc.
} 
and motherhood) as primary for any woman (Moser, 1993). Discourse properties like these are, as van Dijk (1993) said, geared towards the production or activation of an episodic mental model confirming negative attitudes about the powerlessness, of girls in sciences, amongst others. Once established, he elaborates, such negative social (curriculum) representations may in turn be used in the formation of models that monitor discriminatory acts. This formation of general attitudes, consisting of general opinions such as 'girls are less motivated to do science', are acquired more or less directly by generalised statements in discourse (ibid.), as shown in discourse extracts. Van Dijk's argument, to which we subscribe, is that such social representations of a particular group sustain inequality.

Another piece of the discourse fragment "opportunities towards education for all are there, the fault is theirs (girls) not the system" is also ideologically laden. From an intertextual analysis, one can read functionalist, instrumentalist views of gender equality in education shaped with a patriarchal parlance. Gender equality is seen in a narrow sense that includes physical access: the belief that once girls and boys are exposed to the same curriculum, taught by the same teacher, read the same book, there is equality. This assumption overlooks the existing gendered social relations in school bureaucracies and the systems of instruction in the societies of which they are part. Adequate learning and teaching linked to the prevailing curriculum does not necessarily address the intensity and force with which views about gender inequality are held and transmitted. Nor does it overcome the consequences of a long history of gender inequality (Unterhalter and North, 2011).

Van Dijk (1993) also noted denial and legitimation as 'strategies' used to maintain dominance and inequality. For example the phrase "opportunities towards education for all are there" is a good example of a case in which a teacher educator is denying that there is anything more the system can do. As discussed above, the denial hinges on a functionalist tenet that the curriculum offers both boys and girls equal access to curriculum resources. Justification and legitimation are read in: "the fault is theirs (girls), not the system; they are capable/able but they put less effort". Implicit in this discourse is the system (curriculum) is just and the fault is theirs (the 'girls').

Discourse fragment 2: Responding to: What role can teacher education play to improve female participation in sciences? What efforts are you putting in place to ameliorate the situation/alert/impart knowledge, skills and attitudes to future teachers?

int1: The education lacks to the girl child that we are all the same there is nothing like subjects for boys and some for girls [sic]. Teachers don't convey such messages to girls.

int6: I sensitise our own trainee teachers towards this... last week I spoke about it giving a lived example of ... 8 out of 10 who did well in a test were females.

int2: $\quad$...no college policy in gender responsive pedagogy, there should be some national policy to find mechanisms to promote girls' access into sciences.

As discussed above, it is obvious from the surface meaning of this discourse fragment that teacher educators are not aware of the existence of policies that can assist them in bringing about gender responsive pedagogies into their curriculum practices. This shows a policy practice gap which raises tensions around SMTs teacher education in this case study. A critical analysis of the text fragment however, provides deeper insight. Fairclough's (2001) notion of member's resources was quite helpful in this case. He viewed member's resources as ideologies e.g. assumptions of culture, social relationships and social identities which are constituted by power

Cultural and Pedagogical Inquiry, Fall 2016, 8(2), pp. 11-22

ISSN 1916-3460 @ 2016 University of Alberta

http://ejournals.library.ualberta.ca/index.php/cpi/index 
relations but at the same time either reproduce or change these power relations by participating in the social process of struggle.

The text fragment: "the education lacks to the girl child that we are all the same there is nothing like subjects for boys and some for girls", may look sincere but it is also manipulative. The discourse producer dismisses the patriarchal ideological barrier that girls face and assumes that if every teacher repeatedly tells girls and boys that "we are all the same there is nothing like subjects for boys and some for girls", then there is gender equality. Additional cues "teachers don't convey such messages to girls" confirm the belief that what is needed is simply conveying the message. The producer appears to lack understanding of deeper cultural issues that impact on the ontology and epistemology of SMTs education.

Features of member resources related to social relationships and social identities are also implicit in the fragment: "I sensitise our own trainee teachers towards this...there is no college policy in gender responsive pedagogy; there should be some national policy to find mechanisms to promote girls' access into sciences".

Teacher educators may be seen as being responsible for the problem of gender inequality, but this discourse fragment reveals a deeper structural problem related to a lack of appropriate policy guidance to assist them to implement the necessary curriculum initiatives. The text "I sensitise our own trainee teachers towards this" implies 'I am doing my level best in the given circumstances'. The discourse shows that SMTs teacher education practice is constituted by power relations between those who decide on the curriculum and those who implement what is decided. Such power relations not only have the potential to perpetuate the status quo, but also to weaken, if not eliminate agential identities of individuals. The conclusion from this text analysis from the case study is that there was no concrete curriculum innovation for gender responsive pedagogy. The SMTs teacher education curriculum operates in a gender ${ }^{4}$ neutral manner, a situation that will make the practice gendered. By not addressing the patriarchal hegemony embedded in SMTs, it is perpetuating gender blind ${ }^{5}$ curriculum practices.

\section{Conclusion and recommendations}

Discourse fragments discussed in this paper reveal that the teacher educators in this case study have limited conception of gender responsive pedagogies. The fundamental belief of SMTs teacher educators that "girls believe that science is for boys/is difficult; girls are socialised to do easier stuff; some (girls) look up to men to look after them in life" is what Bourdieu (2000) referred to as 'doxa': fundamental, deep-founded unthoughtful beliefs, taken as self-evident, universal and they inform their actions and thoughts in their field (curriculum practice) (p. 169). SMTs curriculum development has been informed for centuries by patriarchal and instrumentalist ideas and this plays an important role in this doxa, being the fundamental constraint in the uptake of gender responsive pedagogy in SMTs education.

Having said that, the analysis in this paper could be criticised for being too deterministic and leaving little room for agency and for neglecting the role of consciousness in practice. Archer (2007) provides an account of identity and identity emergence that recognizes that people are not

\footnotetext{
${ }^{4}$ Claim that one is indifferent to issues of gender, as he/she has no ultimate gender practice. It assumes that all people are affected by programmes (or polices) in the same way.

${ }^{5}$ Gender blind people fail to realise that policies, programmes and activities can have different effects on men and females and this often leads to rigidity and unchanging attitudes.

Cultural and Pedagogical Inquiry, Fall 2016, 8(2), pp. 11-22

ISSN 1916-3460 (C) 2016 University of Alberta

http://ejournals.library.ualberta.ca/index.php/cpi/index
} 
only determined or produced by structures, such as discursive structures; people have agency. Reflexivity, she added, enables persons "to consider themselves in relation to their (social) contexts and vice versa. Her argument is that such deliberations, enable people to evaluate their situations and determine concerns and future actions" (Birkett, 2011, p. 3).

Drawing on Archer's theoretical arguments we call upon support for reflexivity among SMTs teacher educators points of practice. Teacher education students require support that will help them to scrutinize their practices as it relates to establishing gender responsive pedagogy in SMTs education. It is imperative in this paper that policy formulation alone is not enough for gender curriculum re-orientation. Re-orienting curriculum is not likely to be successful if it is done superficially without shaking the instrumentalist and patriarchal roots that shape values of (practitioners) teacher educators. In this regard, our recommendation is that for successful curriculum re-orientation to occur, there is also substantial need to engage with invisible or implicit mediational properties of institutional structures that shape human thought and action. 


\section{References}

Aikenhead, G. (2002). Whose scientific knowledge? The colonizer and the colonized. Retrieved January 23, 2007, from http://www.usask.ca/

Archer, M. (2007). Making our way through the world: Human reflexivity and social mobility. Cambridge: Cambridge University Press.

Birkett, H. (2011). A Critical Realist Approach to Identity. Retrieved March 27, 2012, from http://www.organizzazione.unina.it/cms7/proceedings/proceedings_stream_12/Birkett.pdf

Bourdieu, P. (2000). Pascalian Meditation. (R. N. Stanford, Trans.) London: Stanford UP.

Chetcuti, D. and Kioko, B. (2012). Girls' Attitudes towards Science in Kenya, International Journal of Science Education, 1-19.

Chikunda, C. (2010). Assessing the level of gender awareness of science teachers: the case of Zimbabwe's two education districts. African Journal of Research in Mathematics, Science and Technology Education.

Chikunda, C. (2013). Exploring and expanding capabilities, sustainability and gender justice in Science Teacher Education: Case Studies in Zimbabwe and South Africa. Unpublished PhD Dissertation. Rhodes University.

Charles Chikunda. (2014): Identifying Tensions around Gender-responsive Curriculum Practices in Science Teacher Education in Zimbabwe: An Activity Theory Analysis. African Journal of Research in Mathematics, Science and Technology Education, DOI: 10.1080/10288457.2014.956409

Christidou, V. (2011). Combining students' voices with the voices of school Science, teachers, and popular science. International Journal of Environmental and Science Education. 6(2), 141-159.

Clegg, A. (2007). Girls into science: a training module. UNESCO.

Dorsey, B. (1996). Academic Women at the University of Zimbabwe: Career Prospects, Aspirations and Family Role Constraints. Zimbabwe Journal of Educational Research, 1(3), 13-17.

Daniels, H. (2012). Institutional culture, social interaction and learning. Learning, Culture and Social Interaction, 1(1), 2-11.

Dieltiens, V., Unterhalter, E., Letsatsi, S., and North, A. (2009). Gender blind, gender-lite: a critique of gender equality approaches in the South African Department of Education. Perspectives in Education, 27(4), 365-374.

Fairclough, N. (2001). The Discourse Analysis of New Labour: Critical Discourse Analysis. In M. Wetherell, Discourse as Data, 2001 (pp. 229-266). London: Sage. 
Fairclough, N. (2008). A dialectical-relation approach to critical discourse in social research. In R. Wodak and M. Meyer (Eds.) Methods in Critical Discourse Analysis. London: Sage.

Gordon, R. (1995). Educational Policy and Gender in Zimbabwe. Zimbabwe Journal of Educational Research. 13, 4.

Hopkins, C. and McKeown, R. (2005). Mobilising for education for sustainable development: Towards a global learning space based on regional centres of expertise. UN University, UNU-IAS. Retrieved June 24, 2005 from http://www.aip.org/statistics/trends/reports/hsreport

Kabeer, N. (1994). Gender Aware Policy and Planning: A Social Relations Perspective. In M. Macdonald, Gender Planning in Development Agencies: Meeting the Challenges. Oxford: Oxfam: UK.

Kalu, I. (2005). Classroom interaction in physics lessons, relative to students' sex. African Journal of Research in Mathematics, Science and Technology, 9(1), 55-66.

MacKay, J. and Parkinson, J. (2010). Gender, self-efficacy and achievement among South African Technology teacher trainees. Gender and Education, 22(1), 87-103.

Madziva, J. S. (2000). Gender and Curriculum: Teaching girls science and mathematics. Policy makers' Seminar. Ministry of Education, Sport and Culture, Kadoma, Zimbabwe.

Mawere, D. (2013). An Evaluation of the implementation of the National Gender Policy in Teacher Education in Zimbabwe. International Journal of Asian Social Science, 3(2), 443-450.

McSharry, G. and Jones, S. (2002). Television programming and advertisements: help or hindrance to effective science education? International Journal of Science Education, 24, 487-497.

Millennium Development Goals country report for Zimbabwe. (2010). Millennium Development Goals Status Report Zimbabwe, Government of Zimbabwe.

Morna, C. L., and Jambaya-Nyakujara, L. (2011). SADC Gender Protocol Barometer. Johannesburg: Southern Africa Gender Protocol Alliance.

Moser, C. (1993). Gender planning and development. Theory, Practice and Training. London: Routledge.

Mutekwe, E., Maphos, C., Machingambi, S., Ndofirepi, A. P, and, Wadesango, N. (2013). Exploring the Teachers' Role in the Social Construction of Gender through the Hidden Culture Curriculum and Pedagogy: A Case of Zimbabwe. J Soc Sci, 37(3), 307-318.

Mutekwe, A. and Mutekwe, C. (2012). Manifestations of the gender ideology in the Zimbabwean school curriculum. Journal of educational and instructional studies in the world. 2(3), 193-207. 
Ndawi, O. (1987). Pedagogical Possibilities of African Cultural Activities from Zimbabwe, in P. Obanya (Ed.) Pedagogical Possibilities of African Games, World Confederations of the Organisations of the Teaching Profession (WCOTP), Morges, Switzerland.

Nhundu, T. 2007. Mitigating gender-typed occupational preferences of Zimbabwean primary school children: The use of biographical sketches and portrayals of female role models. Sex Roles, 56, 639-649.

Rutoro, E., Jenjekwa, V., Runyowa, J., Chipato, R. (2013). Gender equity dilemma and teacher education in Zimbabwe: the quest for gender justice. International Journal of Education and Research, 1(10), 1-14

Sheyholislami, J. (2008). Identity, discourse, and media: The case of the Kurds. Canadian Journal of Communication, 1-15.

Siegel, M. A. and Ranney, M. A. (2003). Developing the Changes in Attitude about the Relevance of Science (CARS) questionnaire and assessing two high school science classes. Journal of Research in Science Teaching, 40, 757-775.

Sinnes, A. T. (2004). Three approaches to gender equity in science education. Nordic Studies in Science Education (Nordina), 2, 1-6.

Sjøberg, S. (2002). Science and technology education in Europe: Current challenges and possible solutions. Connect: UNESCO International Science, Technology, and Environmental Education Newsletter, 27, 1-5.

Unterhalter, E. and North, A. (2011). Responding to the gender and education. Millennium Development in South Africa and Kenya: Reflections on education rights, gender equality, capabilities and global justice. Compare: A Journal of Comparative and International Education, 41(4), 495-511.

van Dijk, T. A. (1993). Principles of critcals discourse analysis. Discourse and Society, 249-283.

van Dijk, T. A. (2001). Critical discourse analysis. In H. Hamilton (Ed.), Handbook of Discourse Analysis (pp. 352-371). Oxford: Basil Blackwell.

Wertheim, M. (1995). Pythagoras' trousers: God, physics and the gender wars. New York: W. W. Norton.

Zimbabwe National Gender Policy. (2004). Harare: Ministry of Gender and community Development. 